\title{
Equine Obstructive Colic Associated with Heavy Parascaris equorum Infection
}

\author{
Mamta Singh $^{1}$, Mukesh Shakya ${ }^{2}$, H.K. Mehta ${ }^{1}$ and B.C. Parthasarathi ${ }^{3}$ \\ ${ }^{1}$ Department of Veterinary Medicine, ${ }^{2}$ Department of Veterinary Parasitology, College of \\ Veterinary Science \&Animal Husbandry, Mhow-453 446 (M.P.), India \\ ${ }^{3}$ Division of Parasitology, ICAR-IVRI, Izatnagar, Bareilly- 243122 (U.P.), India \\ *Corresponding author
}

\begin{abstract}
A B S T R A C T
Keywords

Colic, Parascaris equorum, Horse

Article Info

Accepted:

15 April 2019

Available Online:

10 May 2019

Equine Colic term used to describe abdominal pain in horse. There are several predisposing factors that leads to colic condition in horses such as accumulation gas, intestinal displacement, impacted food mass, parasites etc. A three years' young mare brought to the TVCC, CVSc \& AH, Mhow (M.P.) with the history of lying down on the back, sweating, rolling on the ground, reluctant to move and cessation of urination and defecation. The animal collapsed and died after twelve hours of symptomatic treatment. On post mortem examination revealed several balls of Parascaris equorum parasites impacted all over the small and large intestine. On the basis of clinical symptoms and post mortem examination disease condition was confirmed as nematode parasite induced obstructive colic.

\section{Introduction}

Colic is one of the most common problems in equine practice (Parry et al., 1986), frequent and important cause of death, and considered as the most important disease condition of horses encountered by practicing veterinarians (Radostits et al., 2007). Colic can be divided into two major categories; gastrointestinal and non-gastrointestinal (Smith et al., 2002) in which gastrointestinal being the common. Gastrointestinal colic can be caused by different conditions, ranging from a harmless spasmodic colic to a lifethreatening strangulating obstruction (Van der

Linden et al., 2003). Most of the time the obstructions that cause colic are due to impactions by feed, sand, intestinal parasites etc. The most common sites of impaction are in the ileum, cecum, and pelvic flexure of the large colon (White and Dabareiner, 1997).

The current communication reports a case of obstructive colic in a female horse due to heavy Parascaris equorum infestation. In horses a small number of worm loads can be tolerated but heavy infestation of worms can cause impaction or obstruction of intestine and severity of the disease directly related to the load of parasitic worm.
\end{abstract}




\section{Materials and Methods}

\section{History and clinical examination}

A three-year-old white female horse was presented to the Teaching Veterinary Clinical Complex, College of Veterinary Science and Animal Husbandry, Mhow (M.P.) with the history of unable to stand, lying down on the back, sweating, rolling on the ground, reluctant to move and cessation of urination and defecation. The animal was having a rectal temperature of $99^{\circ} \mathrm{F}$. On clinical examination, gastric distension along with abdominal pain noticed and on back racking the rectum seems to be empty (Fig. 1).

\section{Laboratory examination}

Blood sample was collected in anticoagulant coated vials for the estimation of $\mathrm{Hb}$, TLC, DLC, SGPT and serum creatinine.

\section{Results and Discussion}

Based on the above history and clinical signs the present case was tentatively diagnosed as obstructive colic, out of any specifications.

The hematological examination revealed Heamoglobin (Hb) $13.5 \mathrm{~g} \%$, total leukocyte count (TLC) 15350/cu mm, differential leukocyte counts with neutrophil 53\%, lymphocyte $32 \%$, monocyte $14 \%$, eosinophil $0 \%$, basophil $1 \%$ and in the biochemical examination, Serum glutamate pyruvate transaminase (SGPT) and creatinine noted as $23 \mathrm{U} / \mathrm{L}$ and $7.87 \mathrm{mg} / \mathrm{dl}$ respectively. No blood parasites were observed in the blood smear examination.

The mare was treated with flunixine meglumine, frusemide, multivitamins, sodium acid phosphate, liquid paraffin along with the fluid therapy using normal saline and ringer's lactate. The animal does not respond to the treatment and collapsed $12 \mathrm{hrs}$ later.

\section{Post- mortem examination}

On postmortem examination, mare was found with congested lungs, pale coloured heart, congested stomach, enlarged spleen, impacted and congested small intestine and most importantly, clogged mass of round worms in small and large intestines (Fig. 2) were observed. The collected parasites examined under microscope and confirmed as Parascaris equorum. On the basis of clinical symptoms and post mortem examination disease condition was confirmed as Obstructive colic due to heavy Parascaris equorum infection.

Equines are the hosts of dozens species of internal parasites that infect none other domestic animals (Reinemeyer and Nielsen, 2009). Gastro-intestinal parasites cause acute medical problems in horses including diarrhoea, intestinal impaction or irritation (colic) which results in slow growth in young horses, poor performance, acute bouts of colic, and death in severe condition. Age is important in regard to susceptibility to infection and disease, foals and yearlings are usually the most affected while adults over five years of age harbor more or moderate numbers of worms (Shite et al., 2015). Parasites of the greatest concern in horses are large strongyles, small strongyles, roundworms, pinworms, stomach bots, and tapeworms (Aiello and Moses, 2016). The larval stage of the Strongylus vulgaris is also causes colic, consequently thromboembolism and arteritis also developed during the migration of the parasite larval stage in the host (Reinemeyer and Nielsen, 2009). Presence of large number of Tapeworm causes significant pathological changes in ileocecal junction, which can be lead to different types of colic namely spasmodic colic, ileal impaction colic, and possibly 
intussusception and rupture of cecum (Proudman et al., 2003). The larval stage cyathostomes also causes severe damage to the gut wall which resulting in diarrhoea, colic, and a mortality rate upto 50\% (Corning et al., 2009). Fifty percent of all deaths in horses may be related to gastrointestinal parasitism (Hudson et al., 1992). Infection of equines with endo-parasites were ranked at fourth through $9^{\text {th }}$ over the most common medical problems of equine in India (Katoch et al., 1998).Worm obstructions are seen in horses which are heavily infected by internal parasites and are not on a routine deworming programme.

Fig.1\&2 Permanent recumbent horse \& clogged mass of round worms in intestine

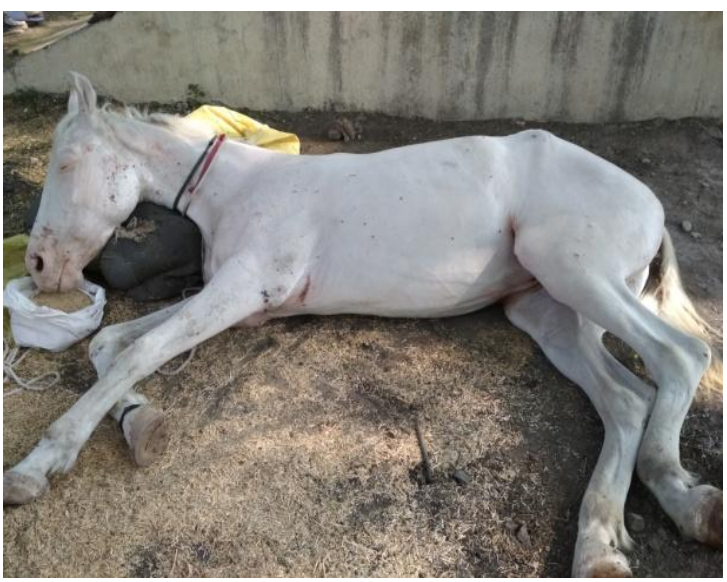

Parasitic disease generally reflects concurrent or historical management standards (Reinemeyer and Nielsen, 2009). Effective deworming sessions twice or thrice in a year should be practiced as a prophylactic measure. The three major classes of anthelmintics available for parasite control in horses are the avermectins, benzimidazoles, and pyrantels (Aiello and Moses, 2016). Considering the development of resistance to individual anthelminthics, it is always preferred to follow a combination anthelminthic therapy. Continuous monitoring and routine deworming programme in equines lower the incidence of parasitic colic.

\section{Acknowledgements}

Authors are highly thankful to the Dean, College of Veterinary Science and Animal Husbandry, Mhow for providing the necessary facilities required for conducting the research work.

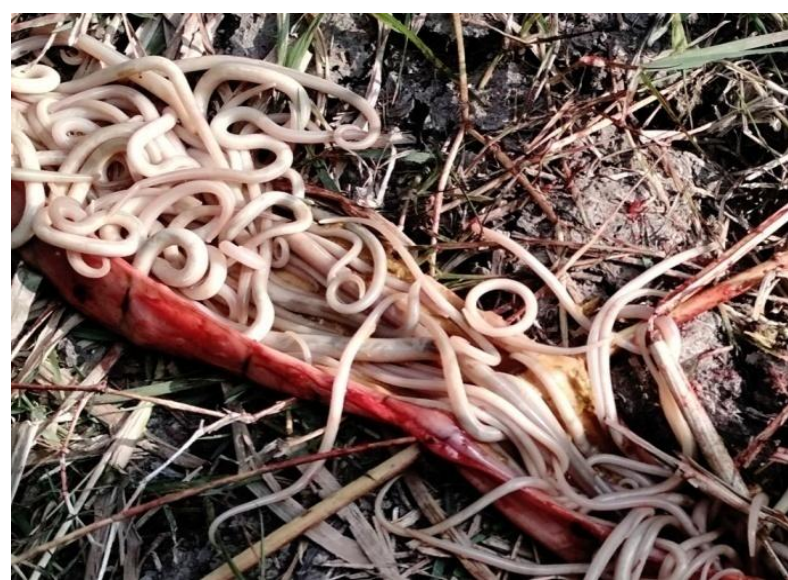

\section{References}

Aiello, S.E. and Moses, M.A. 2016. Health management interaction: horses, The Merck Veterinary Manual, Merck \& Co., Inc, Kenilworth, NJ, USA, 11th Edn: 2156.

Corning, S. 2009. Equine cyathostomins: a review of biology, clinical significance and therapy. Parasites and Vectors, 2(Suppl 2): S1, 1-6.

Hudson, D., Grotelueschen, D. and Rice, D. 1992. G92-1095 Equine internal parasites historical materials from University of Nebraska-Lincoln Extension: 1151.

Katoch, R., R.K. Mandial and R.K. Agnihotri, 1998. Endoparasites of horses in mid hill areas of Himachal Pradesh. Proceedings of 10th National Conference of Veterinary Parasitology, Dec. 4-6, Jabalpur, India. Pp. 70-71.

Parry, B.W. 1986. Prognostic evaluation of 
equine colic cases. Compendium on Continuing Education for the Practising Veterinarian, 8:S98-S104.

Proudman, C.J., 2003. Diagnosis, treatment, and prevention of tapeworm-associated colic. J. Equine Vet. Sci., 1(23), pp.6-9.

Radostits, O.M., Gay, C.C., Hinchcliff, K.W. and Constable, P.D. 2007. Veterinary medicine - A textbook of the diseases of cattle, horses, sheep, pigs, and goats, $10^{\text {th }}$ Edn., Elsevier Saunders, USA: 215232

Reinemeyer, C.R. and Nielsen, M.K. 2009. Parasitism and colic. Veterinary Clinics: Equine Practice, 25(2): 233-245.

Shite, A., Admassu, B. and Abere, A., 2015.
Large Strongyle Parastes in Equine: A Review. Adv. Biol. Res., 9(4), pp.247252.

Smith, B.P. 2002. Large animal internal medicine, St Louis: Mosby., USA, 3rd Edn: 108-111.

Van Der Linden, M.A., Laffont, C.M. and van Oldruitenborgh-Oosterbaan, M.M.S., 2003. Prognosis in equine medical and surgical colic. J. vet. intern. med., 17(3), pp.343-348.

White II, N.A. and Dabareiner, R.M., 1997. Treatment of impaction colics. Vet. Clin. N. Am.: Equine Pract., 13(2), pp.243-259.

\section{How to cite this article:}

Mamta Singh, Mukesh Shakya, H.K. Mehta and Parthasarathi, B.C. 2019. Equine Obstructive Colic Associated with Heavy Parascaris equorum Infection. Int.J.Curr.Microbiol.App.Sci. 8(05): 1676-1679. doi: https://doi.org/10.20546/ijcmas.2019.805.193 